\title{
VẬN DỤNG KẾ TOÁN TRÁCH NHIỆM XÃ HỘI TRONG CÁC DOANH NGHIỆP NIÊM YẾT VIỆT NAM: RÀO CẢN VÀ GIẢI PHÁP
}

\author{
TRẦN NGỌC HÙNG, NGUYỄN THI THÚY HẠNH \\ Khoa Kế toán kiểm toán, Truờng Đại học Công nghiệp TPHCM, Việt Nam \\ tranngochung@iuh.edu.vn
}

Tóm tắt. Thời gian gần đây trong giới học thuật rộ lên các nghiên cứu về trách nhiệm xã hội của doanh nghiệp (corporate social responsibility - CSR), một khái niệm được các nhà học thuật xây dựng từ trước thế chiến thứ hai và được phát triển rộng rãi vào thập niên 60 của thế kỷ trước. Mặc dù không phải là vấn đề quá mới mẻ tại Việt Nam, tuy nhiên hàng loạt các sự cố ảnh hưởng đến môi trường và xã hội gần đây tại Việt Nam như Fomorsa (Hà Tĩnh), Rạng Đông (Hà Nội) ... lại một lần nữa gióng lên hồi chuông cảnh báo về tầm quan trọng của việc nhận thức và áp dụng chế độ kế toán cho trách nhiệm xã hội của doanh nghiệp trong các doanh nghiệp Việt Nam. Dựa trên một số lý thuyết nền tảng về kế toán trách nhiệm xã hội (social and environmental accounting - SEA), bài báo sử dụng các phương pháp nghiên cứu định tính để tổng hợp các bài học trên thế giới khi áp dụng SEA, nghiên cứu đối chiếu với thực trạng vận dụng SEA trong các doanh nghiệp Việt $\mathrm{Nam}$, từ đó chỉ ra các rào cản và dựa vào đó đề ra các giải pháp nhằm nâng cao chất lượng thông tin SEA cũng như khả năng áp dụng trong các doanh nghiệp Việt Nam.

Từ khóa: trách nhiệm xã hội của doanh nghiệp (CSR), kế toán trách nhiệm xã hội (SEA), doanh nghiệp Việt Nam (DNVN)

\section{APPLYING SOCIAL AND ENVIRONMENTAL ACCOUNTING IN VIETNAMESE ENTREPRISES: BARRIERS AND SUGGESTED SOLUTIONS}

\begin{abstract}
Recently in the academic community there has been a great attention in corporate social responsibility (CSR) studies, a concept developed by academics before the World War II and widely expanded in the 1960s. Although it is not a new problem in Vietnam, but due to numerous recent incidents impacting to environment and social in Vietnam such as Fomorsa (Ha Tinh), Rang Dong (Hanoi City) ... once again raising the sounded alarm about the significance of acknowleding and applying accounting regime for corporate social responsibility in Vietnamese enterprises. Based on a number of fundamental theories about social and environmental accounting (SEA), the paper uses qualitative research methods to synthesize wordwide lessons when applying SEA, doing comparison with current application of SEA in Vietnamese enterprises. Basing on findings, the paper aims to point out barriers and propose solutions to improve the quality of SEA information as well as the applicability in Vietnamese enterprises.
\end{abstract}

Key words. corporate social responsibility (CSR), social and environmental accounting (SEA), Vietnamese enterprises

\section{1. ĐẠT VẤN Đề}

Bất chấp những khó khăn do ảnh hưởng chiến tranh thương mại Mỹ - Trung, trong 8 tháng đầu năm 2019 kinh tế Việt Nam vẫn đạt được các con số ấn tượng. Mặc dù Chính phủ Việt Nam luôn nhấn mạnh mục tiêu phát triển bền vững, trong đó kết hợp chặt chẽ, hợp lý và hài hòa giữa phát triển kinh tế với phát triển xã hội và bảo vệ tài nguyên, môi trường, bảo đảm quốc phòng, an ninh và trật tự an toàn xã hội (QĐ số: 432/QĐ-TTg - 2012). Tuy nhiên hàng loạt các sự cố ảnh hưởng đến môi trường và xã hội gần đây tại Việt Nam như đầu độc biển khu vực miền Trung của Fomorsa (Hà Tĩnh), cháy gây sự cố đầu độc do thủy ngân phát tán của Công ty Rạng Đông (Hà Nội) ... lại một lần nữa gióng lên hồi chuông cảnh báo về tầm quan trọng của việc nhận thức và áp dụng chế độ kế toán cho trách nhiệm xã hội của doanh nghiệp trong các doanh nghiệp Việt Nam. Việc khuyển khích động viên hay bắt buộc các doanh nghiệp khi hoạt động phải hạch toán, theo dõi cũng như công bố các thông tin về trách nhiệm xã hội cần phải được nhìn nhận dưới góc độ khoa học, từ đó rút ra các bài học nhằm giúp cho doanh nghiệp $(\mathrm{DN})$ không chỉ nhận thức được lợi 
ích khi tuân thủ kế toán trách nhiệm xã hội, mà còn giúp DN định hướng rõ ràng cách thức hạch toán các chi phí - doanh thu trong thực tiễn hoạt động.

\section{TỔNG QUAN LÝ THUYẾT}

\subsection{Các nghiên cứu về CSR và SEA}

Mặc dù khá phổ biến nhưng từ trước đến nay trong giới học thuật có rất nhiều cách định nghĩa khác nhau về CSR. Theo Bowen (1953), khái niệm trách nhiệm xã hội hàm ý đề cập đến nghĩa vụ của doanh nhân khi tuân thủ hay theo đuổi các chính sách để đưa ra các quyết định hoặc các hành động nhằm đạt được các mục tiêu và giá trị mà xã hội của chúng ta mong muốn. Tương tự như vậy, Carroll (1979) lập luận rằng CSR bao gồm toàn bộ trách nhiệm của một $\mathrm{DN}$ như: kỳ vọng về kinh tế, pháp lý, đạo đức..vv.. mà xã hội nơi DN đó hoạt động kỳ vọng tại một thời điểm nhất định. Xét về mối tương quan giữa $\mathrm{DN}$ và xã hội thì CSR chính là cách các công ty quản lý hoạt động kinh doanh để tạo ra tác động tích cực đến xã hội. Do đó, các công ty không những cần tính đến chất lượng quản lý của họ (cả về con người và quy trình) mà còn cần phải quan tâm về bản chất và số lượng tác động do họ gây ra đối với xã hội trong các lĩnh vực khác nhau (Baker, 2004). Một DN cần xác định vai trò của mình trong xã hội và từ đó thực hiện các tiêu chuẩn cần thiết thuộc phạm trù đạo đức, trách nhiệm, pháp lý và xã hội. Hay nói một cách khác, một DN trong xuyên suốt quá trình hoạt động của mình có nghĩa vụ xem xét không chỉ lợi ích của khách hàng, nhân viên, cổ đông mà còn của cả cộng đồng và hệ sinh thái (Gössling và Vocht, 2007; Lindgreen và ctg., 2008; Gokulsing, 2011). Vào năm 2005, Kotler và Lee đã đưa ra sáu sáng kiến chính mà theo đó hầu hết các hoạt động liên quan đến CSR đều tạo ra tác động tích cực đến DN. Thứ nhất, các DN cung cấp quỹ, đóng góp bằng hiện vật hoặc các nguồn lực khác để xây dựng nhận thức và mối quan tâm cho các lý tưởng xã hội hoặc để hỗ trợ gây quỹ, tham gia hoặc tuyển dụng tình nguyện viên thực hiện các lý tưởng đó. Thứ hai, các cam kết của $\mathrm{DN}$ về việc quyên góp một tỷ lệ phần trăm doanh thu cho một lý tưởng cụ thể. Thứ ba, các $\mathrm{DN}$ hỗ trợ phát triển và/hoặc thực hiện chiến dịch thay đổi hành vi nhằm cải thiện sức khỏe, an toàn, môi trường hoặc phúc lợi cộng đồng. Thứ tư, các DN trực tiếp đóng góp cho quỹ từ thiện dưới hình thức quyên góp tiền mặt và/hoặc các hoạt động tình nguyện. Thứ năm, các DN hỗ trợ và khuyến khích các đối tác bán lẻ và/hoặc thành viên nhượng quyền tình nguyện dành thời gian của họ để hỗ trợ các tổ chức và sự nghiệp cộng đồng địa phương. Cuối cùng, các DN áp dụng và thực hiện các hoạt động kinh doanh tùy ý hỗ trợ các lý tưởng xã hội để cải thiện phúc lợi cộng đồng và bảo vệ môi trường. Từ các nghiên cứu và khái niệm đa dạng, các học giả cũng đồng thời đưa ra nhiều mô hình khác nhau về CRS. Điển hình như Carroll (1991) khi phân biệt giữa các loại trách nhiệm tổ chức khác nhau đã đề xuất mô hình kim tự tháp ngụ ý một hệ thống các trách nhiệm từ cơ bản bao gồm các trách nhiệm kinh tế và pháp lý đến nâng cao theo định hướng xã hội về trách nhiệm đạo đức và từ thiện. Tác giả lập luận rằng các DN là các đơn vị kinh tế cơ bản trong xã hội, có trách nhiệm về việc tạo ra lợi nhuận (xét về bản chất kinh tế) và trách nhiệm thiện nguyện (trách nhiệm đạo đức). Trách nhiệm kinh tế là trách nhiệm cơ bản nhất của một $\mathrm{DN}$, nó phản ánh bản chất của một công ty là một tổ chức kinh doanh tạo ra lợi nhuận. Trách nhiệm kinh tế ngụ ý rằng xã hội mong muốn DN sản xuất những hàng hóa và dịch vụ theo yêu cầu và tạo ra lợi nhuận như một sự khích lệ hoặc phần thưởng cho sự hoạt động hiệu quả của DN. Các trách nhiệm pháp lý đòi hỏi sự kỳ vọng về việc tuân thủ pháp luật và "làm theo luật". Từ quan điểm này, xã hội hy vọng DN sẽ hoàn thành sứ mệnh kinh tế trong khuôn khổ được đặt ra bởi hệ thống pháp luật của xã hội (Jamali và ctg., 2008). Crane và Matten (2007) nói thêm rằng tất cả các $\mathrm{DN}$ cố gắng chịu trách nhiệm xã hội đều phải tuân thủ luật pháp, và xã hội mong muốn các $\mathrm{DN}$ hành động có đạo đức (theo các tiêu chuẩn, chuẩn mực hoặc kỳ vọng của xã hội) đối với các bên liên quan, bao gồm người tiêu dùng, nhân viên, cổ đông và cộng đồng.

Tuy nhiên sau đó vào 2003, Schwartz và Carroll đã nêu bật những hạn chế nhất định trong kim tự tháp CSR của Carroll. Đầu tiên, kim tự tháp gợi ý một hệ thống phân cấp các miền CSR, theo đó người ta có thể kết luận rằng miền ở trên cùng quan trọng hơn miền ở cơ sở. Đây rõ ràng không phải là loại ưu tiên CSR mà Carroll dự định trong kim tự tháp CSR của mình. Ví dụ như đối với trách nhiệm từ thiện, đây là lớp đại diện nhỏ nhất của kim tự tháp, liên quan đến sự sẵn lòng của $\mathrm{DN}$ để nâng cao chất lượng cuộc sống của các bên liên quan thông qua quyên góp từ thiện và hỗ trợ tổ chức hoàn toàn tự nguyện và được xã hội mong muốn. Do đó các trách nhiệm từ thiện đôi khi ở cùng cấp độ với đạo đức. Tuy nhiên, điểm khác biệt là nó không được coi là hành vi phi đạo đức nếu DN không đóng góp tiền của họ cho các 
chương trình nhân đạo (Carroll, 1991). Thứ hai, khung kim tự tháp không thể nắm bắt hoàn toàn bản chất giao thoa của các miền CSR.

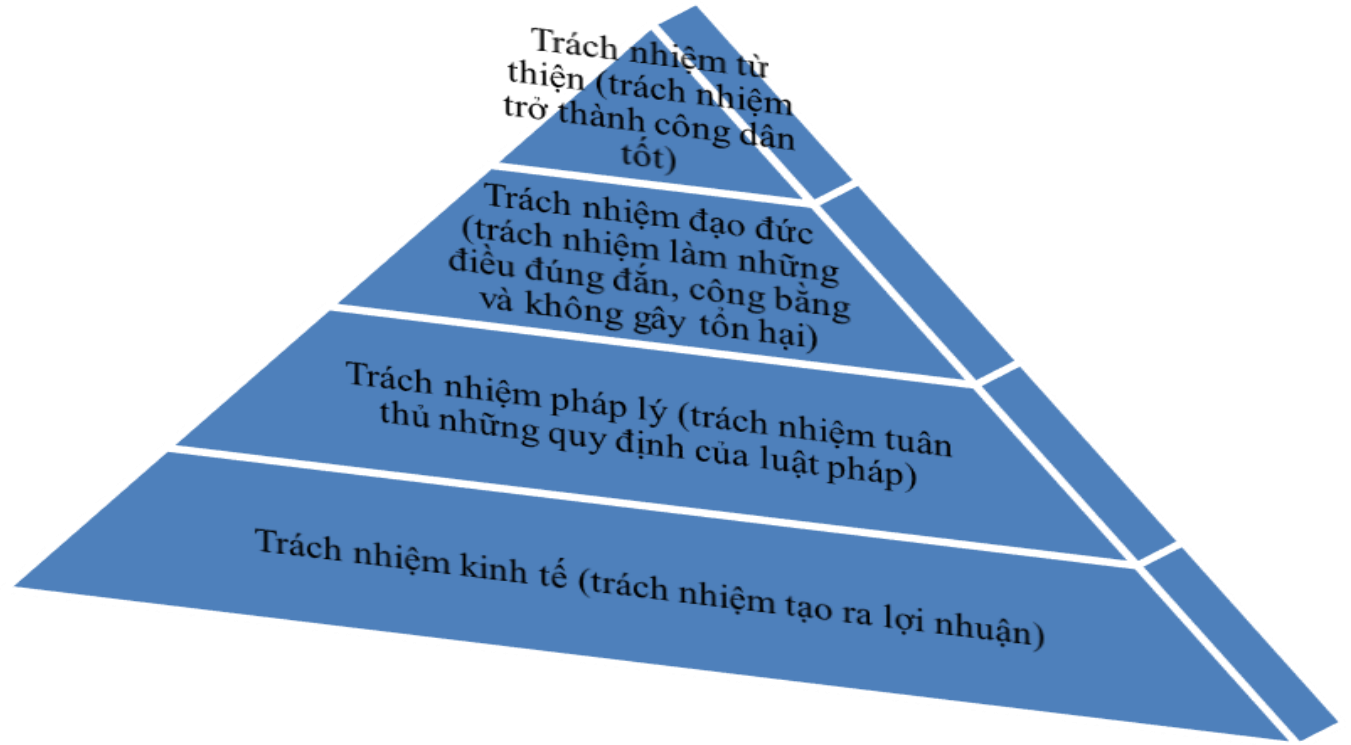

Hình 2.1. Kim tự tháp CSR của Carroll (1991)

Từ đó, họ đề xuất một cách tiếp cận khác để khái niệm hóa CSR, mô hình Venn ba miền (trách nhiệm kinh tế, pháp lý và đạo đức) mang lại bảy loại CSR từ sự giao thoa của ba miền cốt lõi. Tuy nhiên, ngoại lệ với mô hình này là loại từ thiện, nếu tồn tại được duy trì dưới các lĩnh vực đạo đức và / hoặc kinh tế. Hình 2 minh họa khung mô hình Venn có nguồn gốc từ Schwartz và Carroll (2003).

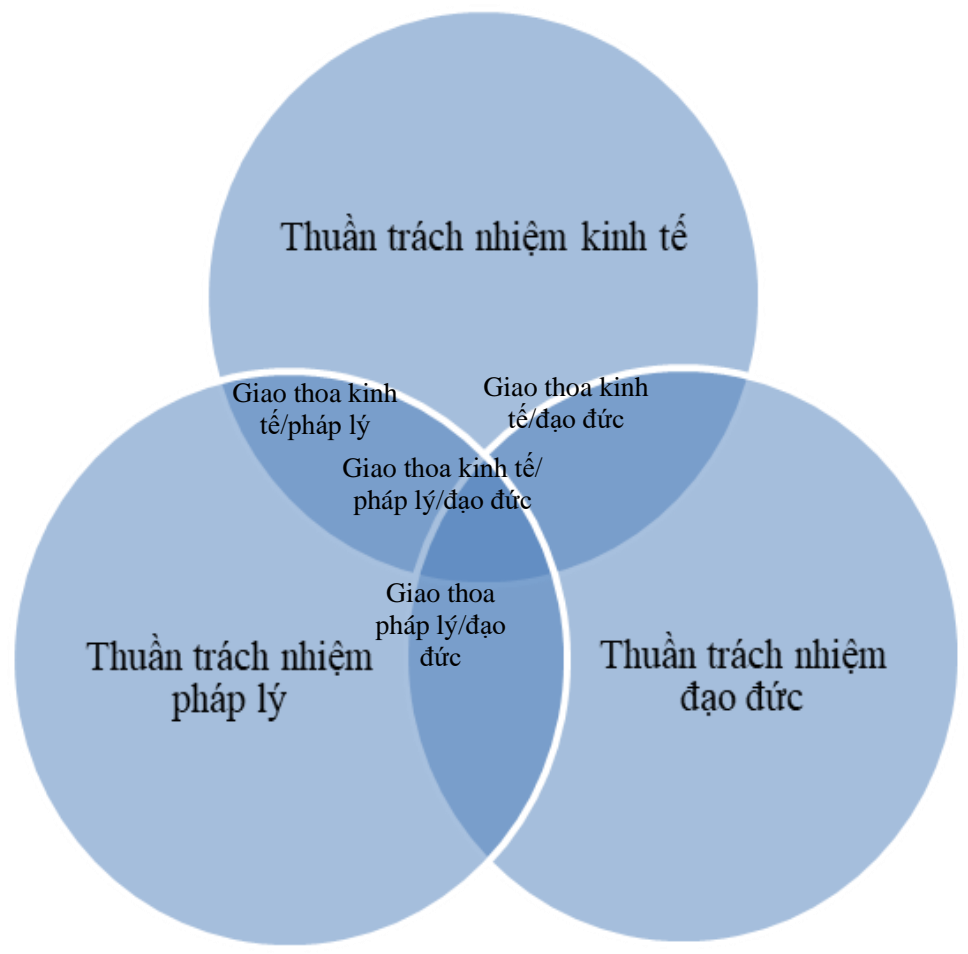

Hình 2.2. Mô hình Venn CSR của Schwartz và Carroll (2003)

Khi xem xét CSR ở các nước đang phát triển, Visser (2006) dựa vào các nghiên cứu thực nghiệm được thực hiện bởi Pinkston và Carroll (1996), Edmondson và Carroll (1999), và Burton và ctg. (2000) để nhấn mạnh thực tế rằng văn hóa có thể có ảnh hưởng quan trọng đến các ưu tiên CSR được nhận thức. Như vậy, kim tự tháp Carroll (1991) được chấp nhận rộng rãi được xem xét lại trong bối cảnh các nước đang 


\section{VẬN DỤNG KÊ TOÁN TRÁCH NHIỆM XÃ HộI TRONG CÁC DOANH NGHIỆP NIÊM YÊT VIỆT NAM: RÀO CẢN VÀ GIẢI PHÁP}

phát triển. Tuy nhiên Visser cho rằng thứ tự của các lớp CSR ở các nước đang phát triển khác với kim tự tháp cổ điển của Carroll (1991). Ở các nước đang phát triển, ngay cả khi trách nhiệm kinh tế vẫn được chú trọng nhất, hoạt động từ thiện được ưu tiên cao thứ hai sau đó là trách nhiệm pháp lý và đạo đức. Điều này được giải thích một phần bởi sự gắn bó truyền thống với hoạt động từ thiện bởi thực tế đó là cách trực tiếp nhất ngay lập tức cải thiện điều kiện sống trong môi trường xung quanh và cũng bởi truyền thống văn hóa liên quan tới tôn giáo, sự phụ thuộc và tương hỗ ở các nước đang phát triển. Ngược lại, áp lực tuân thủ luật pháp hiện hành ít hơn so với các nước phát triển (Visser, 2006).

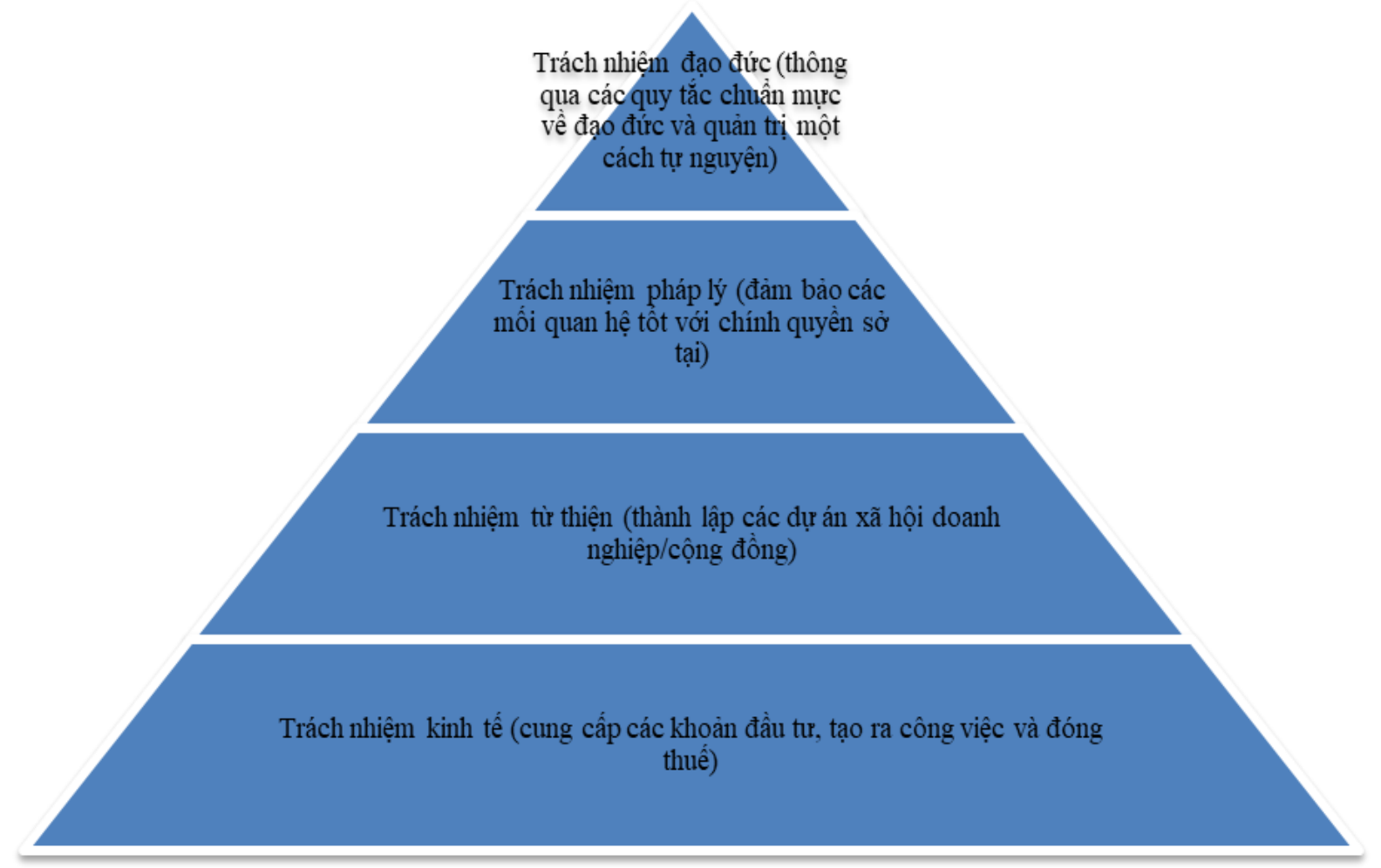

Hình 2.3. Kim tự tháp CSR của Visser (2006)

Không chỉ đơn giản tham gia vào các hoạt động CSR, điều quan trọng không kém là việc các DN cung cấp thông tin về các hoạt động này cho các bên liên quan (Holder-Webb và ctg., 2009). Ngoài ra, lời kêu gọi công bố thông tin phi tài chính đã tăng lên để đáp ứng với nhận thức rằng báo cáo tài chính bỏ qua thông tin nổi bật về công ty (Adams và ctg., 2011). Báo cáo tài chính thực sự mô tả một bức tranh giới hạn của công ty thông qua việc chỉ cung cấp các số liệu tài chính. Do đó, sự liên quan của thông tin phi tài chính đã tăng đáng kể qua các năm. Sự xuất hiện của báo cáo phi tài chính có thể được coi là một nỗ lực nhằm tăng tính minh bạch đối với các hành động của công ty liên quan đến các vấn đề xã hội và môi trường (Nielsen và Thomsen, 2007). Hơn nữa, phải thừa nhận rằng việc tiết lộ thông tin phi tài chính là điều cần thiết để giảm sự bất cân xứng thông tin tồn tại giữa ban quản lý và các bên liên quan chính cũng như cho phép các nhà đầu tư đánh giá tốt hơn các lĩnh vực hoạt động chính và hỗ trợ một cách nhìn rộng hơn về hoạt động của công ty xét về mặt tổng thể xã hội (Huang và Watson, 2015). Cùng với sự quan tâm ngày càng tăng để tham gia vào các hoạt động CSR, ngày nay, các tập đoàn trên toàn thế giới ngày càng tự nguyện tiết lộ thông tin về hiệu suất CSR của họ. Không còn nghi ngờ gì nữa, có rất nhiều động lực có thể giải thích cho việc các DN tham gia vào thực tiễn báo cáo CSR (Holder-Webb và ctg., 2009). Và ngày nay CSR - cam kết tự nguyện cho các mục tiêu phi kinh tế vượt ra ngoài yêu cầu pháp lý - ngày càng trở thành trung tâm của các cuộc tranh luận trong cộng đồng nói chung và trong giới học thuật nói riêng (Schmitz và Schrader, 2015).

Cùng với sự phát triển của CSR, các khái niệm và nghiên cứu về kế toán trách nhiệm xã hội (KTTNXH) cũng thay đồi và phát triển qua các thời kỳ. Vào năm 1987, nhóm nghiên cứu của Gray đã định nghĩa về KTTNXH là quá trình truyền tải các tác động đến xã hội và môi trường gây ra bởi các hoạt động kinh tế của tổ chức đối với các nhóm lợi ích cụ thể trong xã hội nói riêng và toàn xã hội nói chung. Vì vậy, KTTNXH liên quan đến việc mở rộng trách nhiệm của các tổ chức (đặc biệt là các $\mathrm{DN}$ ), ngoài vai trò 
truyền thống là cung cấp các thông tin tài chính cho các chủ sở hữu vốn, đặc biệt là các cổ đông. Một phần trách nhiệm mở rộng như vậy được xác định dựa trên giả định rằng các $\mathrm{DN}$ có trách nhiệm rộng lớn hơn là việc đơn giản chỉ kiếm tiền cho các cổ đông của họ (Gray và ctg., 1987). Tuy nhiên sau đó định nghĩa này tiếp tục được bổ sung thêm chi tiết đối với kế toán môi trường (được coi là một phần của KTTNXH), được coi là bao gồm tất cả các lĩnh vực kế toán có thể bị ảnh hưởng bởi phản ứng của $\mathrm{DN}$ đối với các vấn đề môi trường, bao gồm các lĩnh vực kế toán sinh thái mới (Gray và ctg., 1993).

Trong khi đó, dưới góc nhìn của Mathews (1993) thì KTTNXH có liên quan tới việc công bố thông tin một cách tự nguyện, cả về mặt định tính và định lượng được thực hiện bởi các tổ chức để thông báo hoặc ảnh hưởng đến một loạt các đối tượng. Công bố định lượng có thể ở khía cạnh tài chính hoặc phi tài chính. Và sau đó vào năm 1995, Mathews và Perera nhất mạnh rằng ít nhất thì KTTNXH có nghĩa là mở rộng công bố thông tin vào các lĩnh vực phi truyền thống như cung cấp thông tin về nhân viên, sản phẩm, dịch vụ cộng đồng và ngăn ngừa hoặc giảm ô nhiễm. Tuy nhiên, thuật ngữ KTTNXH cũng được sử dụng để mô tả một hình thức kế toán toàn diện có tính toán đến các tác động ra bên ngoài ... Các tổ chức thuộc lĩnh vực công cũng có thể được đánh giá theo cách này, mặc dù hầu hết các học giả nghiên cứu về chủ đề KTTNXH dường như quan ngại hơn với các tổ chức tư nhân (Mathews và Perera, 1995).

Theo Schaltegger và Burritt (2005), các tập đoàn đi đầu đang nhận ra rằng hoạt động có trách nhiệm xã hội làm cho hoạt động kinh doanh có ý nghĩa và sự cam kết với các bên liên quan thực sự có thể giúp cải thiện hiệu quả kinh doanh của doanh nghiệp. Đồng với quan điểm trên, Deloitte Touche Tohmatsu, một doanh nghiệp lớn điển hình của khu vực Đông Nam Á, khuyên rằng: Các nhà quản trị doanh nghiệp đang ngày càng hành động theo trách nhiệm xã hội bởi vì nó giúp các doanh nghiệp giảm thiểu rủi ro, bảo vệ thương hiệu doanh nghiệp và mang lại lợi thế cạnh tranh. Việc thực hiện trách nhiệm xã hội của doanh nghiệp được thể hiện qua báo cáo trách nhiệm xã hội hay còn được gọi là báo cáo phát triển bền vững. Theo WBCSD (2003) báo cáo phát triển bền vững mang lại những lợi ích kinh doanh như: tạo ra giá trị tài chính; thu hút vốn dài hạn và giúp doanh nghiệp có điều kiện tài chính thuận lợi; nâng cao nhận thức của nhân viên, thúc đẩy và sắp xếp nhân viên và thu hút nhân tài; cải thiện hệ thống quản lý doanh nhiệp; giúp doanh nghiệp nhận thức về rủi ro; khuyến khích doanh nghiệp đổi mới và cải tiến liên tục; nâng cao danh tiếng của doanh nghiệp.

\subsection{Các nghiên cứu về các nhân tố tác động đến SEA}

Thế giới toàn cầu hóa hiện nay đã chứng kiến sự bất bình đẳng xã hội gia tăng và sự xuất hiện của các vấn đề môi trường toàn cầu (Levy và ctg., 2007). Các $\mathrm{DN}$ đang chịu áp lực mạnh mẽ về việc chịu trách nhiệm những tác động của họ đối với xã hội và môi trường nơi họ hoạt động. Những điều này đã dẫn đến các $\mathrm{DN}$ phải tham gia vào các hoạt động về $\mathrm{CSR}$, và từ đó dẫn đến việc áp dụng KTTNXH nhằm cố gắng đo lường lợi ích xã hội mà họ cung cấp cũng như chi phí xã hội mà họ gây ra (Kalunda, 2007).

Theo Mohammad (2011) thì việc áp dụng KTTNXH không những bị tác động bởi các nhân tố nội tại bên trong DN như trình độ và ý thức của đội ngũ nhân viên (bao gồm các kế toán viên) mà còn còn bởi các nhân tố bên ngoài như các ưu đãi chính sách, hướng dẫn về thực hiện chính sách kế toán trong DN hay các quy định ràng buộc về môi trường (đến từ các cơ quan quản lý).

Ví dụ như nếu các cơ quan quản lý ban hành chính sách ưu đãi thuế hay miễn thuế sẽ khuyến khích các DN cam kết với việc áp dụng KTTNXH. Bên cạnh đó, việc có sẵn các quy định luật pháp liên quan đến các hoạt động môi trường cho các $\mathrm{DN}$ buộc áp dụng kế toán môi trường (có các quy định xử phạt trong trường hợp không áp dụng) hay các khuôn khổ, khái niệm chung về KTTNXH và các phương pháp áp dụng, hệ thống kế toán để hướng dẫn kế toán về thực hành KTTNXH ... cũng sẽ làm gia tăng việc áp dụng KTTNXH. Kết quả nghiên cứu này cũng phù hợp với các nghiên cứu trước đó của Metwally (2001), Khoury và Naesa (2007) khi họ chỉ ra rằng các ưu đãi thuế sẽ đóng góp hiệu quả trong việc chống ô nhiễm môi trường thông qua ưu đãi thuế cho tài sản cố định thân thiện với môi trường và giảm chi phí giảm ô nhiễm từ cơ sở thuế vì sẽ khuyến khích các $\mathrm{DN}$ trình bày trong các báo cáo kế toán tài chính kèm theo nội dung về các quy trình và hoạt động liên quan đến môi trường bên trong hệ thống kế toán môi trường để có thể tận dụng những ưu đãi này, đặc biệt là các DN hoạt động trong lĩnh vực lưu ý kiểm soát ô nhiễm môi trường. Các ưu đãi và miễn thuế (dù vĩnh viễn hay tạm thời trong một khoảng thời gian nhất định) có thể có tác động rất lớn đến việc vận dụng KTTNXH nhằm hướng tới hoạt động kinh tế một cách thân thiện với môi trường, áp dụng công nghệ và môi trường kỹ thuật thân thiện.

Khi tiến hành khảo sát $57 \mathrm{DN}$ niêm yết trên sàn giao dịch chứng khoán tại Jordan vào năm 2014, Talah và 
Suleiman (2014) đã phát hiện các nhân tố tác động đến việc vận dụng KTTNXH bao gồm nhu cầu cải thiện chất lượng sản phẩm tiêu dùng, sự phát triển nguồn nhân lực, tình trạng ô nhiễm của môi trường, các dịch vụ cộng đồng tại địa phương $\mathrm{DN}$ hoạt động, các quy định, ràng buộc của hệ thống pháp luật và sự khó khăn khi thiếu khung pháp lý hướng dẫn để hòa hợp số liệu của KTTNXH.

Vào 2018 Langfield-Smith và cộng sự đã tổng hợp các bên liên quan và tác động của các bên liên quan đến việc vận dụng KTTNXH trong các DN như sau:

\begin{tabular}{|c|c|}
\hline Các bên liên quan & $\begin{array}{l}\text { Tác động của các bên liên quan đến việc vận dụng KTTNXH } \\
\text { trong các DN }\end{array}$ \\
\hline Khách hàng & $\begin{array}{l}\text { Sự gia tăng số lượng khách hàng tìm kiếm về các sản phẩm thân thiện } \\
\text { với môi trường }\end{array}$ \\
\hline Cổ đông & Một số cổ đông quan tâm đến giá trị phát triển bền vững \\
\hline Nhân viên & $\begin{array}{l}\text { Một số nhân viên muốn làm việc trong các } \mathrm{DN} \text { có sự quan tâm về } \\
\text { môi trường và cộng đồng }\end{array}$ \\
\hline Các nhà đầu tư & $\begin{array}{l}\text { Một số nhà đầu tư hướng đến các khoản đầu tư có trách nhiệm với xã } \\
\text { hội }\end{array}$ \\
\hline Các ngân hàng & $\begin{array}{l}\text { Một số ngân hàng lớn trên thế giới (như Westpac, ANZ, Ngân hang } \\
\text { quốc gia Úc) đã tham gia ký kết Nguyên tắc xích đạo, trong đó thể } \\
\text { hiện cam kết chỉ tài trợ cho các dự án có trách nhiệm xã hội cũng nhu } \\
\text { kế hoạch quản trị môi trường. }\end{array}$ \\
\hline Các nhà cung ứng & $\begin{array}{l}\text { Bất kỳ đâu trong chuỗi cung ứng, nhu cầu của một nhà cung ứng về } \\
\text { sự phát triển bền vững có thể tác động lên các nhà cung ứng trong } \\
\text { chuỗi, hay nói cách khác xu hướng lựa chọn các nhà cung ứng sẽ trao } \\
\text { các cơ hội cho các bên tham gia thể hiện vai trò trách nhiệm với môi } \\
\text { trường và xã hội }\end{array}$ \\
\hline Các tổ chức cộng đồng & $\begin{array}{l}\text { Các nhóm cộng đồng có thể tác động lên các } \mathrm{DN} \text { trong việc đáp ứng } \\
\text { nhu cầu địa phương như nhu cầu về tạo công ăn việc làm hay phục } \\
\text { hồi môi trường địa phương. }\end{array}$ \\
\hline $\begin{array}{l}\text { Các tổ chức phi chính phủ } \\
\text { (NGOs) }\end{array}$ & $\begin{array}{l}\text { Các nhóm hoạt động phi chính phủ (NGOs) thường đóng vai trò bảo } \\
\text { vê môi trường cunng như công đồng }\end{array}$ \\
\hline Truyền thông & $\begin{array}{l}\text { Giới truyền thông có thể hoạt động theo quyền lợi riêng hoặc đại diện } \\
\text { cho các bên liên quan khác. Sự phát triển của internet góp phần rất } \\
\text { lớn làm gia tăng sự ảnh hưởng của giới truyền thông. }\end{array}$ \\
\hline Chính phủ và các quy định & $\begin{array}{l}\text { Một vài quốc gia có những luật và quy định giám sát những tác động } \\
\text { đến môi trường và xã hội, yêu cầu bắt buộc có những báo cáo về sự } \\
\text { tác động cũng như có quy định xử phạt nếu vi phạm }\end{array}$ \\
\hline
\end{tabular}

\section{NỘI DUNG, PHƯƠNG PHÁP NGHIÊN CÚU}

Trong nghiên cứu này để phân tích thông tin liên quan đến việc thực hiện các hoạt động thể hiện TNXH được lấy trên báo cáo thường niên cũng như trên Báo cáo TNXH riêng biệt của các DN niêm yết, nhóm tác giả sử dụng chủ yếu phương pháp phân tích thống kê mô tả. Phương pháp này trước đây cũng đã được nhiều tác giả tại các quốc gia khác nhau sử dụng trong nghiên cứu thực trạng vấn đề báo có thông tin TNXH (Haji, 2013). Dữ liệu thu thập cho nghiên cứu này gồm các nguồn dữ liệu điện tử như: dữ liệu online, các website và nguồn internet được sử dụng để tải các báo cáo thường niên và báo cáo $\mathrm{TNXH}$ của các DN Việt Nam niêm yết. Dựa vào các lý thuyết nền tảng và các nghiên cứu trước đây trên thế giới về KTTNXH và các nhân tố tác động đến KTTNXH trong DN, tác giả chọn mẫu các DN hiện nay đang phải thực hiện báo cáo phát triển bền vững (là sản phẩm đầu ra của KTTNXH) là các công ty đại chúng. Mặc dù không còn mới mẻ trên thế giới, tuy nhiên hiện nay chính phủ Việt Nam mới chỉ ban hành Thông tư 155/2015/TT-BTC để yêu cầu các công ty đại chúng thực hiện báo cáo thường niên bao gồm công bố thông tin về phát triển bền vững. Theo chuẩn phân ngành toàn cầu GICS ${ }^{\circledR}$. (Global Industry Classification Standards - Chuẩn phân ngành toàn cầu được phát triển bởi tổ chức MSCI và S\&P Dow Jones Indexes) các công ty đại chúng được phân thành 10 lĩnh vực (sectors) chi tiết bao gồm: 

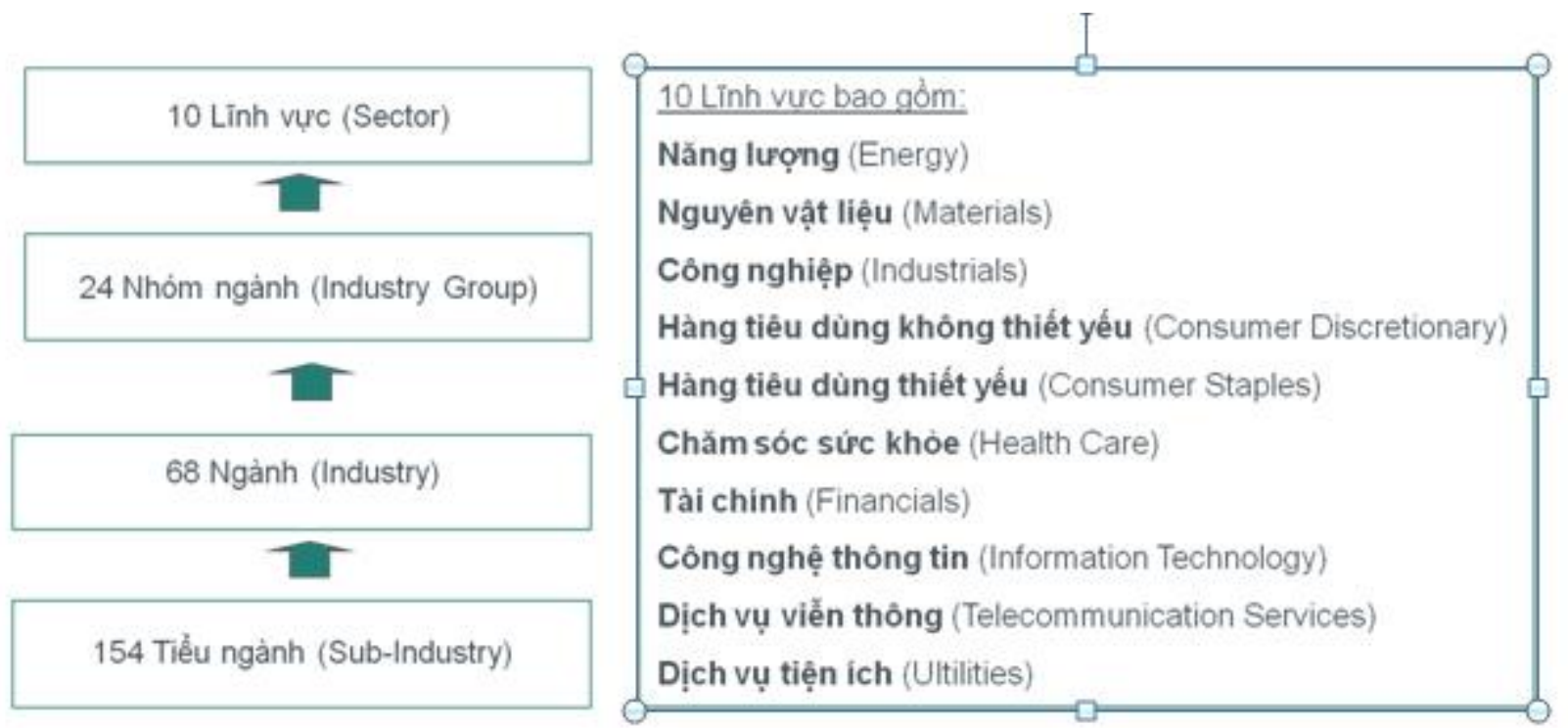

Nguồn: tác giả tổng hơp

Hiện nay các công ty đại chúng Việt Nam được phân loại thành công ty đại chúng quy mô lớn (vốn điều lệ lớn hơn 120 tỷ đồng) và công ty đại chúng (vốn điều lệ lớn hơn 10 tỷ đồng và nhỏ 120 tỷ đồng); cũng như theo cách phân chia quản lý tại 3 sàn giao dịch chứng khoán UpCom, HNX và HOSE, nên tác giả sẽ chọn mẫu ngẫu nhiên $30 \mathrm{DN}$ đầu ngành cho 10 lĩnh vực với $3 \mathrm{DN}$ đầu ngành đại diện nằm ở 3 sàn giao dịch chứng khoán khác nhau để xem xét về mức độ chi tiết báo cáo phát triển bền vững (theo phụ luc đỉnh kèm).

\section{THỰC TRẠNG VÀ RÀO CẢN KHI VẬN DỤNG KTTNXH TẠI CÁC DN VIẸT NAM}

\subsection{Thuc trang:}

Trong $30 \mathrm{DN}$ được chọn để khảo sát, đánh giá về công tác KTTNXH, có thể phân thành các nhóm theo các cách phân loại và tiêu chí đánh giá khác nhau như sau:

Thứ nhất, công ty đại chúng quy mô lớn (vốn điều lệ lớn hơn 120 tỷ đồng) tại sàn giao dịch TP HCM HOSE với các điều kiện soát xét chặt chẽ và cao hơn về các tiêu chí khác như thời gian, hiệu quả hoạt động, công bố thông tin và cổ đông (theo nghị định 58/2012/NĐ-CP): bao gồm các DN đầu ngành như Công ty Cổ phần Sữa Việt Nam - Vinamilk (hàng tiêu dùng thiết yếu), Petrolimex (ngành năng lượng), Hòa Phát (ngành nguyên vật liệu), hàng không Vietjet (ngành công nghiệp), Tập đoàn Bảo Việt (ngành tài chính), Tập đoàn Vingroup (ngành bất động sản), Tổng công ty khí Việt Nam (GAS) (ngành dịch vụ tiện ích), Dược Hậu Giang (ngành chăm sóc sức khỏe), Tập đoàn Yeah1 (ngành dịch vụ viễn thông), Thế giới Di động (ngành dịch vụ viễn thông).

Thứ hai, công ty đại chúng (vốn điều lệ lần lượt lớn hơn 30 tỷ đồng và 10 tỷ đồng) tại sàn giao dịch TP HN - HNX và UpCom bao gồm: Công ty cổ phần bánh kẹo Hải Hà, Công ty Cổ phần Hàng tiêu dùng Masan (hàng tiêu dùng thiết yếu); Tổng Công ty Cổ phần Dịch vụ Kỹ thuật Dầu khí Việt Nam, Công ty Cổ phần Lọc Hóa dầu Bình Sơn (ngành năng lượng); CTCP Bột giặt và Hóa chất Đức Giang, Tập đoàn Công nghiệp Cao su Việt Nam (ngành vật liệu cơ bản), CTCP Vicostone, Tổng Công ty Cảng hàng không Việt Nam (ngành công nghiệp), Ngân hàng TMCP Á Châu, Ngân hàng TMCP Quốc tế Việt Nam (ngành tài chính), CTCP Kinh doanh Khí Miền Nam, Tổng Công ty Phát điện 3 (dịch vụ hạ tầng), CTCP Khách sạn và Dịch vụ Đại Dương, CTCP Tổng công ty Truyền hình Cáp Việt Nam( ngành dịch vụ tiêu dùng), Tổng công ty dược Việt Nam, CTCP Dược phẩm Hà Tây, (ngành chăm sóc sức khỏe), CTCP Tin học Viễn thông Petrolimex, CTCP Viễn thông FPT (ngành viễn thông); CTCP Thiết bị Bưu điện, Tổng CTCP Đầu tư Quốc tế Viettel (ngành công nghệ) ...

Các thông tin về phát triển bền vững của các $\mathrm{DN}$ niêm yết trên thị trường chứng khoán bao gồm: quản lý nguồn nguyên liệu, tiêu thụ năng lượng, tiêu thụ nước, tuân thủ pháp luật về bảo vệ môi trường, chính sách liên quan đến người lao động, báo cáo liên quan đến trách nhiêm với cộng đồng địa phương, báo cáo liên quan đến thị trường vốn xanh và không quy định về hình thức trình bày, theo đó $\mathrm{DN}$ có thể lập riêng hoặc trình bày tích hợp báo cáo bền vững trong Báo cáo thường niên (Thông tư số 155/TT-BTC, phụ lục 
số 4 - Báo cáo thường niên, phần II - Tình hình hoạt động trong năm, mục 6 , chính thức có hiệu lực thi hành từ ngày $1 / 1 / 2016)$.

Tác giả đã tiến hành tổng kết tình hình công bố báo cáo phát triển bền vững (là sản phẩm của việc vận dụng KTTNXH) của các DN, tuy nhiên có sự khác biệt rất lớn trong việc vận dụng KTTNXH và báo cáo bền vững giữa các $\mathrm{DN}$ niêm yết giữa các sàn. Nhìn chung hầu hết các DN niêm yết trên sàn HOSE công bố báo cáo phát triển bền vững với các số liệu rất chi tiết cho từng khoản mục, trong đó đặc biệt Vinamilk đã tiến hành công bố báo cáo phát triển bền vững từ năm 2012 (yêu cầu bắt buộc từ năm 2015) và tách biệt với báo cáo thường niên. Đối với những $\mathrm{DN}$ chọn phương pháp lập báo cáo phát triển bền vững theo chuẩn hướng dẫn của GRI (Global Reporting Initiative) như Vinamilk, Petrolimex hay Tập đoàn Bảo Việt thì các số liệu trình bày cho mỗi phần trong hoạt động kinh tế, cộng đồng (môi trường) và xã hội được trình bày rất chi tiết, chứng tỏ DN đã vận dụng KTTNXH trong quá trình hoạt động của mình. Đơn cử như Vinamilk trong năm 2018 đã lựa chọn các chỉ tiêu thuộc các lĩnh vực trọng yếu như: hiệu quả hoạt động kinh tế (GRI 201), phát triển kinh tế địa phương (GRI 413), kiểm soát phát thải và chất thải (GRI 305,306 ), sử dụng năng lượng hiệu quả (GRI 301, 302,303), sức khỏe và an toàn của khách hàng (GRI 416), quan hệ lao động (GRI 401, 403, GRI 404). Báo cáo được trình bày với số liệu rất phong phú, đa dạng và chi tiết, phản ánh đầy đủ vai trò cũng như trách nhiệm của $\mathrm{DN}$ đối với môi trường, xã hội. Tương tự với Tập đoàn Bảo Việt $(\mathrm{BVH})$ khi thuê Công ty TNHH Pricewaterhouse Coopers (PwC) Việt Nam trong việc lập báo cáo bền vững nhằm bảo đảm tính độc lập. Các chỉ tiêu được lựa chọn trình bày đảm bảo nằm trong các lĩnh vực trọng yếu Tập đoàn Bảo Việt ưu tiên thực hiện trong năm 2018, đó là đóng góp gián tiếp về kinh tế (GRI 203), các tiêu chuẩn môi trường (GRI 300), các tiêu chuẩn xã hội (GRI 400) ... Như vậy cho thấy ở đây bên cạnh minh bạch hóa thông tin tài chính, các DN này còn nỗ lực minh bạch hóa thông tin phi tài chính, nhằm cung cấp cho nhà đầu tư và các bên liên quan góc nhìn tổng thể, bao quát mang tính chiến lược về toàn bộ hoạt động của $\mathrm{DN}$ phù hợp với thông lệ quốc tế, giúp thu hút sự quan tâm của các nhà đầu tư cũng như nâng cao vị thế và uy tín đối với khách hàng.

Tuy nhiên đối với các DN còn lại như Tập đoàn Yeah1, Thế giới Di động, Hòa Phát ... thì phần báo cáo bền vững chỉ trình bày một cách chung chung về cam kêt cũng như công việc thực thi đối với trách nhiệm về môi trường và xã hội. Điều này còn thể hiện rõ hơn ở các $\mathrm{DN}$ niêm yết trên sàn $\mathrm{HNX}$ và Upcom, nơi mức độ công bố không tin không bị ràng buộc, và dẫn đến hầu hết các DN niêm yết trên 2 sàn này trình bày báo cáo bền vững một cách sơ sài, chiếu lệ (như Tổng Công ty Cảng hàng không Việt Nam chỉ trình bày số liệu về nộp ngân sách, CTCP Bột giặt và Hóa chất Đức Giang chỉ trình bày số liệu về hoạt động từ thiện ...).

4.2. Rào cản:

Mặc dù ghi nhận tính hữu ích của báo cáo phát triển bền vững, tuy nhiên trong thực tế để vận dụng KTTNXH cũng như lập và công bố dạng báo cáo phi tài chính này đối với DN Việt Nam còn gặp nhiều khó khăn.

Thứ nhất, đây là một vấn đề do còn tương đối mới đối với nhiều DN Việt Nam, kể cả các DN đã niêm yết (văn bản đầu tiên đề cập đến các thông tin liên quan đến BCPTBV là Thông tư số 155/2015/TT-BTC ngày 06/10/2015 của Bộ Tài chính về việc hướng dẫn công bố thông tin trên thị trường chứng khoán). Thông tư này cũng chỉ hướng dẫn các $\mathrm{DN}$ trình bày thông tin chung về công ty, trong đó có các mục tiêu phát triển bền vững về môi trường, xã hội và cộng đồng. Ngoài ra chưa có các hoạt động tuyên truyền, hướng dẫn nên đối với nhiều DN Việt Nam nói chung cũng như các DN niêm yết nói riêng chưa nhận thức được vai trò quan trọng của quá trình vận dụng KTTNXH và công bố báo cáo phát triển bền vững. Thứ hai hiện nay ngoại trừ một số $\mathrm{DN}$ niêm yết đầu ngành như Vinamilk, Tập đoàn Bảo Việt do có sự đầu tư về cả cơ sở vật chất lẫn nguồn lực con người (thậm chí là thuê ngoài dịch vụ tư vấn quốc tế chuyên nghiệp), còn lại đa số các DN rất cần có hướng dẫn, tư vấn cụ thể hơn về nội dung, phương pháp vận dụng KTTNXH cũng như công bố báo cáo phát triển bền vững. Hiện nay trên thị trường có rất nhiều tổ chức tư vấn quốc tế với các hệ tiêu chuẩn khác nhau như Sáng kiến báo cáo toàn cầu (GRI), WRAP (Worldwide Responsible Accredited Production - Sản xuất được công nhận trách nhiệm toàn cầu); Công ước $\mathrm{GHG}$ và chuẩn mực đảm bảo AA1000 ...; điều này khiến cho các DN Việt Nam lúng túng khi chọn loại hình báo cáo để tuân thủ.

Thứ ba, các DN hiện nay đa phần tập trung vào việc tối đa hóa lợi nhuận, không quan tâm đến hoạt động bảo vệ môi trường trong quá trình sản xuất, đảm bảo vệ sinh an toàn thực phẩm hoặc nâng cao đời sống 
của cán bộ nhân viên trong công ty... Theo một khảo sát mới đây của Thủy (2019) thì trong tổng số 100 DN Việt Nam niêm yết được đưa vào nghiên cứu thì có $12 \mathrm{DN}$ không cung cấp bất kỳ thông tin nào liên quan đến TNXH cho các bên liên quan, chỉ có $14 \mathrm{DN}$ trong tổng số $100 \mathrm{DN}$ cung cấp thông tin khá đầy đủ với mức độ thông tin được công bố là trên $80 \%$ theo yêu cầu.

Thứ tư, mặc dù một số DN đã ý thức được việc vận dụng KTTNXH, tuy nhiên, việc thiếu hụt tài chính và nhân lực lại là một rào cản vô cùng quan trọng, đặc biệt là các $\mathrm{DN}$ vừa và nhỏ. Hiện nay hầu hết các trường đại học trên cả nước, ngay cả trong chuyên ngành kế toán, kiểm toán cũng chưa đưa vào chương trình các môn học bắt buộc về kế toán trách nhiệm xã hội hay kiểm toán trách nhiệm xã hội. Do đó trong thực tiễn nguồn nhân lực để đáp ứng yêu cầu của DN về vận dụng KTTNXH hầu như thiếu hụt hoàn toàn, và chủ yếu là dịch vụ do các tổ chức quốc tế hoạt động tại Việt Nam cung cấp như Big Four.

\section{GỢI Ý CÁC GIẢI PHÁP NHẰM NÂNG CAO KHẢ NĂNG VẬN DỤNG KTTNXH TẠI CÁC DN VIÊT NAM}

Việc vận dụng KTTNXH không chỉ giúp các DN củng cố tăng cường mối hợp tác với các bên có liên quan mà còn giúp các $\mathrm{DN}$ tăng cường quản lý rủi ro kinh doanh, nâng cao khả năng thích nghi trong môi trường thay đổi nhanh chóng và nâng cao vị thế cạnh tranh. Nhiều nghiên cứu đã chỉ ra rằng có mối liên hệ tích cực về mối tương quan giữa việc vận dụng KTTNXH và hiệu quả hoạt động dẫn đến việc gia tăng lợi nhuận $\mathrm{DN}$. Trong xu thế hội nhập ngày càng sâu rộng, việc thiếu hoặc không công bố thông tin về phát triển bền vững có thể làm cho DN mất đi cơ hội hợp tác kinh doanh, thu hút nguồn vốn đầu tư từ các nhà đầu tư có trách nhiệm với phát triển bền vững, đặc biệt là các nhà đầu tư quốc tế. Dựa vào các kết quả nghiên cứu ở trên về thực trạng và rào cản, nhóm tác giả đề xuất một số giải pháp nhằm nâng cao chất lượng thông tin cũng như khả năng áp dụng KTTNXH trong các DN Việt Nam niêm yết.

Thứ nhất, đối với các DN Việt Nam niêm yết, về mặt đối nội cần tích cực tăng cường truyền thông nội bộ (thông qua các bảng tin nội bộ về các hoạt động từ thiện, tấm gương người tốt việc tốt, gương sáng trong lao động sản xuất về tiết kiệm nguyên vật liệu, các cuộc thi và giải thưởng về giải pháp xử lý chất thải thông minh ...). Bên cạnh đó tận dụng tối đa tiện ích công nghệ để truyền tải thông tin trên website nhằm chuyển tải ý nghĩa về TNXN đến với các nhân viên trong công ty cũng như giúp họ nhận thức về vai trò của các hoạt động TNXH đối với sự phát triển bền vững của doanh nghiệp. Để làm được điều này DN cần phải có bộ phận chuyên trách để tổng hợp cũng như phân tích thông tin về KTTNXH, từ đó có cơ sở để lập và cung cấp thông tin TNXH đầy đủ và đáng tin cậy. Ngoài ra về mặt đối ngoại, các DN nên trình bày song ngữ Anh - Việt các nội dung không chỉ trên website của mình mà ngay cả các loại báo cáo bền vững hoặc báo cáo thường niên nên nhằm thu hút nhiều hơn sự quan tâm của các nhà đầu tư nước ngoài, cả tổ chức lẫn nhà đầu tư cá nhân.

Thứ hai, đối với các cơ quan ban ngành có liên quan, bên cạnh tài liệu hướng dẫn lập báo cáo phát triển bền vững dựa theo khung Sáng kiến Báo cáo Toàn cầu (GRI) chỉ phù hợp với các tập đoàn, DN quy mô lớn thì Bộ Tài chính cần ban hành sớm và chi tiết các hướng dẫn cụ thể để $\mathrm{DN}$ có cơ sở triển khai KTTNXH. Và quá trình triển khai vận dụng KTTNXH cần có lộ trình cụ thể, giai đoạn đầu cần có những ưu đãi nhất định để khuyến khích các DN thực hiện tốt trách nhiệm của mình đối với cộng đồng, xã hội. Tuy nhiên sau đó bắt buộc triển khai và có các biện pháp chế tài đối với các $\mathrm{DN}$ cố tình không công bố thông tin về trách nhiệm của mình đối với cộng đồng, xã hội, đặc biệt là đối với các DN hoạt động trong các lĩnh vực có thể gây ra tác động xấu, gây hại trực tiếp đến môi trường.

Thứ ba, đối với trường đại học và các tổ chức xã hội đào tạo nghề nghiệp khác cùng đồng hành và sớm có định hướng đào tạo lực lượng lao động đủ khả năng đảm trách công việc KTTNXH nhằm mang lại lợi ích không những cho các bên có liên quan mà còn cho chính $\mathrm{DN}$, cho cả nền kinh tế, cộng đồng và môi trường. Các trường đại học khối ngành kinh tế (đặc biệt là khoa kế toán, kiểm toán) cần phải đưa nội dung TNXH của DN, KTTNXH, báo cáo phát triển bền vững ... vào trong chương trình đào tạo ở các bậc học phù hợp theo lộ trình. Từ đó dần dần đào tạo nguồn nhân lực đáp ứng được nhu cầu của $\mathrm{DN}$, cũng như tạo ra một tầng lớp các nhà quản trị có tâm và có đủ năng lực để giúp nền kinh tế Việt Nam phát triển bền vững trong suốt quá trình hội nhập và phát triển.

\section{TÀI LIỆU THAM KHẢO}

[1] Baker, M., (2004) Corporate social responsibility - What does it mean? [Online]. Available at: http://www.mallenbaker.net/csr/definition.phpv 


\section{VẬN DỤNG KÊ TOÁN TRÁCH NHIỆM XÃ HỘI TRONG CÁC DOANH NGHIỆP NIÊM YÊT VIỆT NAM: RÀO CẢN VÀ GIẢI PHÁP}

[2] Bowen, H.R,. Social responsibilities of the businessman, Harper \& Row, New York, 1953.

[3] Bộ Tài chính, Thông tư số 155/2015/ TT-BTC hướng dẫn công bố thông tin trên thị trường chứng khoán, 2015.

[4] Burton, B. K., Farh, J.L., and Hegarty, W.H., A cross-cultural comparison of corporate social responsibility orientation: Hong Kong vs. United States students, Teaching Business Ethics, vol. 4, no. 2, pp. 151-167, 2000

[5] Carroll, A.B., A three dimensional conceptual model of corporate performance, Academy of Management Review, vol. 4, no. 4, pp. 497-505, 1979.

[6] Carroll, A.B., The pyramid of corporate social responsibility: Toward the moral management of organizational stakeholders, Business Horizons, pp. 39-48, 1991.

[7] Chính Phủ, Nghị định 58/2012/NĐ-CP ngày 20/7/2012 về hướng dẫn Luật chứng khoán 2006 và Luật chứng khoán sửa đổi 2010.

[8] Chính Phủ, Quyết định 432/QĐ-TTg ngày 12/04/2012 phê duyệt Chiến lược Phát triển bền vững Việt Nam giai đoạn $2011-2020$.

[9] Crane, A., and Matten, D., Business ethics, 2nd edition, Oxford University Press Inc., New York, 2007

[10] Gokulsing, R.D., CSR matters in the development of Mauritius, Social Responsibility Journal, vol. 7, no. 2, pp. 218-233, 2011.

[11] Gössling, T., and Vocht, C., Social role conceptions and CSR policy success, Journal of Business Ethics, vol. 74, pp. 363-372, 2007.

[12] Gray, R.H., Bebbington, J. and Walters, D., Accounting for the Environment, ACCA, London, 1993

[13] Gray, R., Owen, D. and Maunders, K., Corporate Social Reporting: Accounting and Accountability, PrenticeHall, London, 1987.

[14] Issam Khoury, Abeer Naesa, The tax system and its impact on the reduction of environmental pollution, 2007.

[15] Hà Thị Thủy, Thực trạng công bố thông tin trách nhiệm xã hội (CSR) của các công ty niêm yết tại Việt Nam, Phát triển \& hội nhập, số 46 (56) - tháng 05 - 06/2019, 2019.

[16] Haji, A. A, Corporate Social Responsibility Disclosures over Time: Evidence from VN, Managerial Auditing Journal, no. 28(7), p.4, 2013.

[17] Holder-Webb, L., Cohen, J., Nath, L., and Wood, D., The supply of corporate social responsibility disclosures among U.S. firms, Journal of Business Ethics, vol. 84, vol. 4, pp. 497-527, 2009.

[18] Huang, X.B., and Watson, L., Corporate social responsibility research in accounting, Journal of Accounting Literature, vol. 34, 1-16, 2015.

[19] Lindgreen, A., Swaen, V., and Johnston, W., Corporate social responsibility: an empirical investigation of US organizations, Journal of Business Ethics, vol. 46, no. 3, pp. 23-29, 2008.

[20] Nielsen, A.E., and Thomsen, C., Reporting CSR - what and how to say it? Corporate Communications, An International Journal, vol. 12, no. 1, pp. 25-40, 2007.

[21] Langfield-Smith, Smith David, Andon Paul, Thorne Hellen, Hilton Ronald W., Management Accounting: Information for creating and managing value, $8^{\text {th }}$ ed, McGraw-Hill Irwin, 2018.

[22] Mathews, M.R., Socially Responsible Accounting, Chapman and Hall, London, 1993.

[22] Mathews, M.R. and Perera, M.H.B., Accounting Theory and Development, 3rd ed., Thomas Nelson Australia, Melbourne, 1995. 
NIÊM YÊT VIỆT NAM: RÀO CẢN VÀ GIẢI PHÁP

[23] Metwally, Talaat Abdel-Azim, Accounting tax dimension for natural resources and the environment: the effectiveness of tax incentives in environmental pollution control, The scientific journal, Tanta University, Vol.1, 2001.

[24] Pinkston, T. S., and Carroll, A. B., A retrospective examination of CSR orientations: Have they changed? Journal of Business Ethics, vol. 15, no. 2, pp. 199-206, 1996.

[25] Schaltegger, S. and Burritt, R.L., Corporate sustainability, The International Yearbook of Environmental and Resource Economics, Edward Elgar, Cheltenham, pp. 185-232, 2005.

[26] Schmitz, J., and Schrader, J., Corporate social responsibility: a microeconomic review of the literature, Journal of Economic Surveys, vol. 29, no. 1, pp. 27-45, 2015.

[27] Schwartz, M.S., and Carroll, A. B., Corporate social responsibility: A three domain approach, Business Ethics Quarterly, vol. 13, no. 4, pp. 503-530, 2003.

[28] Talah và Suleiman, Degree of Participation of Public Industrial Joint Stock Companies in Jordan in Activities Relating to Accounting Social Responsibility, International Journal of Business and Management, vol. 9, no. 7; 2014.

[29] Visser, W., Revisiting Carroll"'s CSR pyramid: An African perspective, In Pedersen E.R., and Huniche, M. (ed.), corporate citizenship in developing countries, Copenhagen, Copenhagen Business School Press, pp. 29-56, 2006.

[30]World Business Council for Sustainable Development (WBCSD), Sustainable Development Reporting: Striking the Balance, WBCSD: Geneva, 2003

[31]https://www.hsx.vn/Modules/Listed/Web/SectorOverview?fid=8138542ddc7d47c7ae40e27206d56b40 truy cập ngày 01 tháng 9 năm 2019.

[32] http://congbothongtin.ssc.gov.vn/idsPortal/ctdc/index.ubck truy cập ngày 01 tháng 9 năm 2019.

Ngày nhận bài: 28/11/2019

Ngày chấp nhận đăng: 02/03/2020 